\title{
ICRF-Induced DD Fusion Product Losses in TFTR
}

\author{
D. S. Darrow, S. J. Zweben, R. V. Budny, H. W. Herrmann, R. Majeski, \\ C. K. Phillips, J. H. Rogers, G. Schilling, J. E. Stevens, J. R. Wilson, \\ Princeton University, Plasma Physics Laboratory, PO Box 451, Princeton, NJ 08543 \\ C. S. Chang, \\ Courant Institute for Mathematical Sciences, New York University, New York, NY 10012 \\ E. F. Jaeger, M. Murakami \\ Oak Ridge National Laboratory, Oak Ridge, TN 37831
}

\begin{abstract}
When ICRF power is applied to TFTR plasmas in which there is no externally-supplied minority species, an enhanced loss of DD fusion products results. The characteristics of the loss are consistent with particles at or near the birth energy having their perpendicular velocity increased by the ICRF such that those near the passing/trapped boundary are carried into the first orbit loss cone. A rudimentary model of this process predicts losses of a magnitude similar to those seen. Extrapolations based upon this data for hypothetical ICRF ash removal from reactor plasmas suggest that the technique will not be energy efficient.
\end{abstract}

\section{Introduction}

ICRF heating has been used in numerous tokamaks to heat the plasma and to increase its fusion reactivity. In some such scenarios, the ICRF waves act to accelerate minority species ions from the cold "bulk" of the distribution. Fast ions can also interact with the ICRF waves and absorb energy. In particular, fusion products ( $3 \mathrm{MeV}$ protons, $1 \mathrm{MeV}$ tritons, and $0.8 \mathrm{MeV}{ }^{3} \mathrm{He}$ ions in DD plasmas and $3.5 \mathrm{MeV}$ alpha particles in DT plasmas) can absorb ICRF energy under some conditions. ${ }^{1}$ This absorption can have several implications. The first is that some of these fusion products might be expelled from the plasma; several methods have been proposed based upon this for ash removal from reactorgrade plasmas. A second possible implication is that ICRF heating scenarios may have to be chosen with care to avoid excessive absorption by the fusion products. ${ }^{2}$

In this paper, we present observations of the loss of DD fusion products due to low levels of ICRF heating in TFTR, report on some initial modeling of the losses, and draw some conclusions about prospects for ash removal and for heating configurations in reactors.

\section{Plasma Parameters, ICRF Heating, and Diagnostics}

In TFTR deuterium plasmas, the most common ICRF heating experiments are done with small amounts of either $\mathrm{H}$ or ${ }^{3} \mathrm{He}$ as the resonant species. 3 However, for the experiments discussed herein, ICRF power was applied to deuterium plasmas with no externallyintroduced minority species. The principal purpose of these experiments was to heat

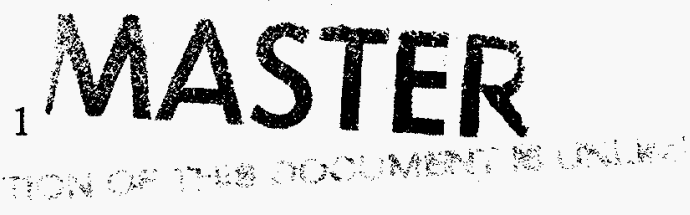


electrons by means of the fast wave. ${ }^{4,5}$ The only resonant species were then the DD fusion products produced by neutral beam injection.

The plasmas studied had the following parameters: $R=2.62 \mathrm{~m}, \mathrm{a}=0.99 \mathrm{~m}, \mathrm{I}_{\mathrm{p}}=1.8 \mathrm{MA}$, $\mathrm{BT}=4.5 \mathrm{~T}, \mathrm{PNBI}=22 \mathrm{MW}, \mathrm{fICRF}=47 \mathrm{MHz}, \mathrm{PICRF}=0-3 \mathrm{MW}, \mathrm{n}_{\mathrm{e}}(0)=5.5 \times 10^{19}$ $\mathrm{m}^{-3}, \mathrm{~T}_{\mathrm{e}}(0)=9 \mathrm{keV}, \mathrm{T}_{\mathrm{i}}(0)=16 \mathrm{keV}$, and $\mathrm{S}_{\text {neut }}=2 \times 10^{16} \mathrm{n} / \mathrm{sec}$. ICRF power was applied by all of the four antennae on TFTR. Because of reflected power and low single-pass absorption, it was not possible to increase the ICRF power above the $3 \mathrm{MW}$ quoted above, even though up to $12 \mathrm{MW}$ may be applied to the plasma in other scenarios. These parameters place the ${ }^{3} \mathrm{He}$ fundamental and the second harmonic of tritium at $\mathrm{R}=2.80 \mathrm{~m}$, inboard of the magnetic axis. Under these conditions, the D majority resonance and the resonances of the principal impurities are well off axis. The DD fusion products though, because of their high velocities, can satisfy the resonance condition $\omega=\Omega_{i}+k_{||} v_{\|}$over a large portion of the plasma. Depending upon their $v_{\|}$, fusion-produced protons can be resonant anywhere in the plasma. Likewise, fusion-produced tritons can be resonant anywhere between $R=2.29 \mathrm{~m}$ and $\mathrm{R}=2.92 \mathrm{~m}$. Given the fusion rate and the slowing down times of the DD fusion products, the maximum central concentration of $1 \mathrm{MeV}$ tritons is very low, roughly $1.5 \times 10^{15} \mathrm{~m}^{-3}$ and that of $3 \mathrm{MeV}$ protons is about $5 \times 10^{14} \mathrm{~m}^{-3}$.

Measurements of the fusion product loss which results from the ICRF were made with the escaping fusion product diagnostic. This diagnostic consists of probes which can measure the pitch angle and gyroradius of escaping fusion products at four poloidal locations (at one toroidal angle), 6 although most of the results are from the probe at $90^{\circ}$ below the midplane. A schematic of one of the probes is shown in Fig. 1, indicating how incident particles are dispersed according to pitch angle and gyroradius. Because the detector separates particles only by gyroradius and not by mass, it is impossible to distinguish between the $3 \mathrm{MeV}$ protons and the $1 \mathrm{MeV}$ tritons produced by DD fusion reactions. A thin aluminum foil covers the inner aperture and excludes hydrogenic ions with energies below $300 \mathrm{keV}$ and helium ions with energies below $900 \mathrm{keV}$. The ions which are able to pass through the foil strike a scintillator plate, and produce light. The image of light produced in the scintillator is carried by a fiber optic bundle to detectors in the basement of the TFTR facility. The detectors include photomultiplier tubes which measure the total light produced in each probe, and an intensified videocamera which records the light pattern on the scintillator. From the pattern of light on the scintillators, analysis may be made of the gyroradii and pitch angles of the particles entering the detectors. Because the diagnostic signal-handling elements near the tokamak are purely optical, this system has very good immunity to rf-produced noise.

\section{Experimental Results}

A number of plasmas were produced with the parameters noted in the preceding section. In some discharges, the ICRF power was steady, while in others, it was modulated at $5 \mathrm{~Hz}$. Fig. 2 shows the ICRF and neutral beam powers, neutron rate, and signals from three of the escaping fusion product detectors versus time for a discharge in which the ICRF power was modulated. This discharge had no significant $\mathrm{MHD}$-induced fusion product loss. In discharges without substantial MHD, the signals from the escaping fusion product probes vary in proportion to the neutron rate. This is because the predominant loss mechanisms of fusion products, first orbit loss and stochastic toroidal field ripple loss, cause a fixed fraction of the production rate to escape when plasma conditions (especially plasma current) are not changing in time. In Fig. 2, there is a clear departure from that proportionality whenever the ICRF power is on, as evidenced by the synchronous enhancement of the loss 


\section{DISCLAIMER}

This report was prepared as an account of work sponsored by an agency of the United States Government. Neither the United States Government nor any agency thereof, nor any of their employees, make any warranty, express or implied, or assumes any legal liability or responsibility for the accuracy, completeness, or usefulness of any information, apparatus, product, or process disclosed, or represents that its use would not infringe privately owned rights. Reference herein to any specific commercial product, process, or service by trade name, trademark, manufacturer, or otherwise does not necessarily constitute or imply its endorsement, recommendation, or favoring by the United States Government or any agency thereof. The views and opinions of authors expressed herein do not necessarily state or reflect those of the United States Government or any agency thereof. 


\section{DISCLAIMER}

Portions of this document may be illegible in electronic image products. Images are produced from the best available original document. 
signal on the $90^{\circ}$ detector. There is also an ICRF-related loss visible in the $45^{\circ}$ detector data. The effect is barely discernible on the $60^{\circ}$ detector for this and other discharges.

Fig. 3 shows the fusion product loss rate at the $90^{\circ}$ detector versus time divided by the total neutron rate, for the same shot shown in Fig. 2. Also shown is the ICRF power versus time, and the time during which the neutral beams are on. When plotted in this way, the effect of the ICRF is more apparent. In this shot, the application of 1.8 MW of ICRF power increases the normalized loss rate by $\sim 25 \%$. The ICRF-related loss is seen to turn on and off very quickly with the ICRF power, requiring $\sim 5 \mathrm{msec}$ to reach a steady value after turn-on, and $\sim 1 \mathrm{msec}$ to stabilize after turn-off. (The power is switched on and off in less than $0.5 \mathrm{msec}$.) These times are short compared to the $90^{\circ}$ pitch angle scattering time for these fusion products, $17 \mathrm{sec}$ for protons and $11 \mathrm{sec}$ for tritons. There is a significant degree of variation in the loss rate during the times when the ICRF is on, but there is as yet no explanation for this behavior, nor any observed correlation of these fluctuations with other signals from the plasma.

The data for Figs. $2 \& 3$ are taken from photomultipliers which measure the total light coming from each probe's scintillator. More detailed information about the pitch angle and gyroradius of the loss can be extracted from video images of the scintillators taken by an intensified videocamera. Fig. 4a presents plots of the light intensity versus gyroradius coordinate in the $90^{\circ}$ detector, integrated over all pitch angles for two time intervals: with and without ICRF. For example, the width of the gyroradius distribution results entirely from the characteristics of the instrumental response. The curve labeled "ICRF Off" in this figure comprises almost exclusively first orbit loss of fusion products at their birth energies. (DD fusion-produced protons and tritons have the same gyroradius at birth.) References 7 and 8 show the agreement between measured gyroradius distributions like that seen in Fig. 4a and numerical modeling of the detector response to first-orbit loss distributions. In Fig. 4a, only the amplitude and not the shape of the gyroradius distribution changes when the ICRF is applied. Hence, the added loss during the ICRF power is inferred to be at the birth energy, within the energy resolution of the detector of $\pm 20 \%$.

Figure $4 \mathrm{~b}$ compares the pitch angle distribution of the lost fusion products, integrated over all gyroradii, for the same data as in Fig. 4a. There is again some instrumental broadening of the distribution. Here, the loss at pitch angles above $67^{\circ}$ is essentially unaffected by the application of ICRF. However, below $67^{\circ}$, there is a significant enhancement to the loss when the ICRF is applied. This enhancement is maximum at a $\sim 58^{\circ}$ pitch angle, which coincides with the fattest banana orbit that enters this probe. The fattest banana orbit, of course, coincides with the boundary between trapped and passing orbits. The instrumental function is such that the observed change is consistent with all the ICRF related loss coming at the fattest banana orbit. The ICRF-induced loss on the $60^{\circ}$ and $45^{\circ}$ probes also appears at the pitch angle of the fattest banana orbit.

Fig. 5 depicts the scaling of the ICRF related enhancement factor, which is the normalized loss during ICRF divided by the normalized loss with no ICRF, versus the ICRF power for a number of shots in the range 66317 to 66342 . There is a definite increase as the ICRF power is raised, and the relationship is approximately linear. At the highest ICRF powers used in this experiment, $3 \mathrm{MW}$, the loss of fusion products is enhanced by a factor of almost 1.8 . 


\section{Modeling of the Loss}

The salient characteristics of the ICRF-induced fusion product loss, derived from the experimental observations above, are these: the loss is at the passing/trapped boundary (fattest banana orbit) in the $90^{\circ}$ detector, is of near birth energy particles, and turns on and off much more rapidly than the collisional pitch angle scattering times of the particles. Three possible ICRF-induced loss processes could produce these signatures: (1) direct increase in the fusion products' perpendicular velocities by the ICRF, which carries barelypassing particles into the first orbit loss cone at the fattest banana orbit ${ }^{9}$; (2) ICRF-induced diffusion of barely-passing particles outward in minor radius until they mirror at the highfield side of their orbits, escaping onto fattest banana orbits; ${ }^{10-14}$ or (3) spiraling outward in minor radius of barely-passing particles due to asymmetric variation of their velocities as they encounter localized ICRF acceleration and collisional slowing down, the result being the same as in (2). 15 Of these, the first process is far faster, according to theory, than the others. Hence, only the first process was modeled and only this process is discussed in what follows.

Fig. 6 shows schematically process (1) above in velocity space. This figure shows only the counter-going (i.e. opposite the direction of the plasma current) portion of velocity space. In addition, it applies only to the particular plasma current used in this experiment, $\mathrm{I}_{\mathrm{p}}=1.8$ $\mathrm{MA}$, and only to a particular magnetic surface, the one at $\mathrm{r} / \mathrm{a}=0.22$. This flux surface is chosen because it is the one which produces the largest first orbit loss signal in the $90^{\circ}$ detector, since its marginally-trapped fusion product orbits are just able to reach that detector. The figure applies to both $1 \mathrm{MeV}$ tritons and $3 \mathrm{MeV}$ protons, since their orbits are identical if they have the same pitch angle. The simplified model used here considers only the flux surface whose characteristics are depicted in Fig. 6. The triangular region is the first orbit loss cone. Note that there is a minimum total velocity below which all particles are confined at this minor radius. Fusion products, in this model, can be affected by two processes: collisional slowing down and ICRF heating. Collisional pitch angle scattering is a much weaker effect than scattering produced by ICRF heating and, hence, is neglected. Slowing down acts to move a particle directly toward the origin in Fig. 6, while ICRF heating causes a vertical motion. The combined effect of collisional slowing down and ICRF heating together is to carry barely passing particles into the loss cone. The stronger the effect of the ICRF compared to the slowing down rate, the larger will be the ICRF enhancement of the first orbit loss. Pitch angle scattering can also carry particles into the loss cone, 16 but at a markedly smaller rate than the ICRF waves, as noted above.

The rate of pitch angle scattering due to the ICRF in a time $\delta$ t may be approximated by 16

$$
\delta v_{\chi}=v_{0}\left(\delta t v_{R F}\right)^{1 / 2} \cos \chi
$$

The effect of ICRF is represented as an effective collisionality, with $v_{R F}=\left(2 p_{a b s} / m_{f} n_{f} v_{f}^{2}\right)$. Here, $m_{f}$ is the fast ion mass, $n_{f}$ is the fast ion density, $v_{f}$ is the fast ion velocity, $p_{a b s}$ is the absorbed ICRF power density in the fast ions, and $v_{R F}$ is the e-folding rate for the energy of the fast ions (neglecting Coulomb slowing down). The first part of the expression for $\delta v_{\chi}$ gives the change in the particle's $v_{\perp}$ due to the ICRF, from which the component acting to change the particle's pitch angle must be computed by multiplying by $\cos \chi$. For the conditions present in these discharges, the PICES code, 17 which is a 3D full wave code developed at ORNL, computes the power absorbed in the tritons, for the case $\mathrm{P}_{\mathrm{RF}}=1.8 \mathrm{MW}$, to be $\mathrm{p}_{\mathrm{abs}}=500 \mathrm{~W} / \mathrm{m}^{3}$. This absorption calculation assumes a central triton 
density of $1.5 \times 10^{15} \mathrm{~m}^{-3}$ (about $2.8 \times 10^{-5}$ of the central electron density), a radial profile of triton density which varies as $\left(1-(r / a)^{2}\right)^{8}$, and a maxwellian distribution function with a temperature of $600 \mathrm{keV}$, roughly approximating the slowing down distribution of the tritons. The distribution function in the experiment is non-maxwellian, but the PICES code, at present, is unable to accommodate such distributions. Hence, the absorbed power figure above is only an estimate. The PICES code is not able to calculate the Doppler-shifted absorption of the waves by $3 \mathrm{MeV}$ protons. In the absence of a suitable computation, the power absorbed by the protons is arbitrarily assumed to be the same as that absorbed by the tritons so that some estimate of their loss rate may be obtained. The parameters of fusionborn protons and tritons, and the corresponding values of $\nu_{R F}$ are given in Table 1 for $r / a=$ 0.22 .

On a given flux surface, there is a minimum velocity, $v_{\min }$, below which ions cannot enter the loss cone. A fast ion will be lost only if its pitch angle at birth is close enough to the passing/trapped boundary that it can be swept into the loss cone before slowing below $v_{\min }$. Hence, the time interval $\delta t$ in Eq. (1) is the time for the fast ion to slow from $v_{0}$ to $v_{\min } . \delta t$ is given, to first approximation, by the collisional slowing down time, although a more exact treatment would have to incorporate the effect of ICRF heating on $\delta t$ also. The change in pitch angle due to the effect of ICRF over the given time $\delta \mathrm{t}$ is then $\delta \chi \approx \delta \mathrm{v}_{\chi} /$ $\mathrm{v}_{\min }$. The values of $\mathrm{v}_{\min }, \delta \mathrm{t}$, and the resultant $\delta \mathrm{v}_{\chi}$ and $\delta \chi$ are also reported in Table 1. From $\delta \chi$ and the pitch angle associated with point $C$ in Fig. 6 , the pitch angle of point $D$ can be calculated. $D$ is the limiting point, beyond which the ICRF is unable to draw thermalizing fast ions into the loss cone. The coordinates of points A through D are listed in Table 2.

Since the loss in the absence of the ICRF waves is first orbit loss, it is convenient to compare the magnitude of the loss during ICRF to first orbit loss. The energy distributions of both losses indicate that near birth energy particles are being lost. Particles are born on the $\mathrm{v} / \mathrm{v}_{0}=1$ circle with a density proportional to $\sin \chi$. To compare the magnitude of the losses, compute the ratio of the birth rate along arc DA to that along arc $\mathrm{AB}$ :

$$
F_{R F}=\frac{\int_{D}^{A} \sin \chi d \chi}{\int_{A}^{B} \sin \chi d \chi}=\frac{\cos \chi_{D}-\cos \chi_{A}}{\cos \chi_{B}-\cos \chi_{D}}
$$

For $1 \mathrm{MeV}$ protons, this ratio is 1.2 ; for $3 \mathrm{MeV}$ protons, using the assumed ICRF power absorption rate, it is 0.70 . By way of comparison, the ratio of loss during ICRF to first orbit loss was only $\sim 0.25$ in the $1.8 \mathrm{MW}$ case shown in Figs. 2-4.

The detector is unable to discriminate between $3 \mathrm{MeV}$ protons and $1 \mathrm{MeV}$ tritons since it only disperses particles based upon their gyroradii. Due to details of the response of the scintillators used in the detectors, 18 about $70 \%$ of the first orbit loss signal is due to protons, and the remaining $30 \%$ due to tritons. If the proton loss rate alone increased by $70 \%$ as predicted above, the total signal to the detector should increase by $49 \%$. If the triton loss rate alone rose by the predicted $120 \%$, the total signal to the detector should increase by $36 \%$. These total to an increase of $85 \%$. This is significantly larger than the total observed increase in loss rate of only $25 \%$. Particles of both species with pitch angles near the passing/trapped boundary can, for the conditions of this discharge, resonate with 
the ICRF waves. Hence, it seems probable that both species contribute to the enhancement of the loss.

There are several shortcomings in the model used above, and these may explain the significant difference between the experimental and model results. The model presented above considers only one magnetic surface, and only one orbit from that surface. A more precise and complete model would compute the actual flux of particles to the chosen detector from the range of flux surfaces and pitch angles which can be seen by that detector. A second shortcoming of this use of the model is the assumption of an absorption rate for the $3 \mathrm{MeV}$ protons. If a suitable calculation of the power absorbed by the protons can be made, it is clear how that can then be used in this model.

There is also an inconsistency between the experimental data and the model presented above. The experimental data indicates that, within the resolution of the detectors, the loss is coming out at the birth energy. In contrast, the model above predicts a distribution of energies between the birth energy and the energy corresponding to the lower edge of the loss cone. The lower edge of the loss cone is at $0.75 \mathrm{E}_{\mathrm{birth}}$.

\section{Discussion}

In the foregoing sections, it has been established that the observed characteristics of the ICRF-related loss are consistent with this loss being due to an increase of the particles' $v_{\perp}$ by ICRF, so that these particles are carried into the first orbit loss cone. In addition, there is rough quantitative agreement between the observed and modeled loss rates. Hence, we believe that the mechanism of the loss has been identified.

It is possible, from the results reported here, to draw some initial conclusions concerning possible applications. The first point to note is that the first orbit loss level is nearly doubled when $3 \mathrm{MW}$ of ICRF is applied. The first orbit loss rate from a $1.8 \mathrm{MA}$ shot in TFTR is $\sim 3 \%$. This means that ICRF expulsion of fusion products can constitute $\sim 3 \%$ of the source rate. (This is only an order of magnitude estimate, since the data in Fig. 2 show that the poloidal distribution of the ICRF-induced loss is not the same as that of the baseline loss.) This loss mechanism depends upon the existence of a first orbit loss cone. For reactor-size devices, such as ITER, that loss cone will exist only near the edge. Hence, loss of alpha particles from the center is likely to be negligible. This would seem to suggest that ICRF-induced alpha loss of this type will not place significant constraints upon ICRF heating scenarios for large devices. Closer to the edge, though, the first orbit loss cone grows large, and so ICRF might be useful as an ash removal method.

There are some limitations to ash removal implied by these observations. First, the ICRFinduced losses observed in this experiment were of fusion products at or near their birth energy. This means that the fusion products have given little or none of their energy to the plasma before being expelled, potentially reducing the self-heating of the plasma and increasing the heat load on the first wall. Second, the energy efficiency of this process is poor. About $2.4 \mathrm{~kW}$ of ICRF power is computed to have been absorbed by the fusion products, resulting in the loss of particles whose total fusion power is $\sim 400 \mathrm{~W}$, to within a factor of two. (There is some inconsistency here, since if all that $2.4 \mathrm{~kW}$ was absorbed by the fusion products, their energies would be $\sim 20 \%$ above their birth energies, something which should have been visible in the loss signals, but was not seen.)

Further work is planned in two broad areas relating to these losses. First, as mentioned above, quantitative numerical models are being formulated to better model the flux to the 
detectors resulting from ICRF. Second, an experiment to try several possible means of influencing alpha particles with ICRF has been proposed for TFTR's DT phase.

\section{Acknowledgments}

We wish to acknowledge the efforts of the TFTR Operations and ICRF groups for their technical support of this experiment. This work was supported by US DoE contract number DE-AC02-76-CHO-3073.

\section{References}

15. J. Zweben, G. W. Hammett, R. L. Boivin, C. K. Phillips, and J. R. Wilson, Nucl. Fusion 32, 1823 (1992)

${ }^{2}$ N. T. Lam, J. E. Scharer, and R. S. Sund, University of Wisconsin Center for Plasma Theory and Computation Report number UW-CPTC 93-1, January 1993

${ }^{3}$ G. Taylor, et al., Princeton Plasma Physics Laboratoy Report number PPPL-2948, January, 1994

${ }^{4}$ M. Murakami, E. F. Jaeger, F. G. Rimini, et al., in Proceedings of the 10th Topical Conference on Radio Frequency Power in Plasmas, Boston, 1993, 48

5 M. Murakami, E. Fredrickson, E. F. Jaeger, et al., in Proceedings of the 20th EPS Conference on Controlled Fusion and Plasma Physics, Lisbon, 1993, vol. 3, 981

${ }^{6}$ S. J. Zweben, R. L. Boivin, M. Diesso, et al., Nucl. Fusion 30, 1551 (1990)

${ }^{7}$ S. J. Zweben, G. W. Hammett, R. L. Boivin, C. K. Phillips, and J. R. Wilson, Nucl. Fusion 32, 1823 (1992)

8 S. J. Zweben, D. S. Darrow, E. D. Fredrickson, and H. E. Mynick, Nucl. Fusion 33, 705 (1993)

${ }^{9}$ C. S. Chang, Phys. Fluids 28, 3598 (1985)

10Liu Chen, J. Vaclavik, and G. W. Hammett, Nucl. Fusion 28, 389 (1988)

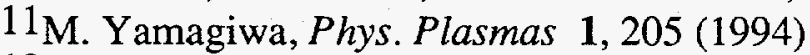

12W. G. F. Core, Nucl. Fusion 29, 1101 (1989)

${ }^{13}$ T. Hellsten, Plasma Phys. Cont. Fusion 31, 1391 (1989)

14 M. A. Kavanen, W. G. F. Core, and T. Hellsten, Nucl. Fusion 32, 787 (1992)

15 C. S. Chang, June-Yub Lee, and Harold Weitzner, Phys. Fluids B 3, 3429 (1991)

16 C. S. Chang, S. J. Zweben, J. Schivell, R. Budny, and S. Scott, Princeton Plasma Physics Laboratory Report No. PPPL-3005, to appear in Phys. Plasmas (1994)

17 E. F. Jaeger, D. B. Batchelor, and D. C. Stallings, Nucl. Fusion 33, 179 (1993)

${ }_{18}$ R. L. Boivin, Z. Lin, L. Roquemore, and S. J. Zweben, Rev. Sci. Instrum. 63, 4418 (1992) 


\section{Table 1}

\begin{tabular}{|c||c|c|}
\hline & $1 \mathrm{MeV}$ tritons & $3 \mathrm{MeV}$ protons \\
\hline \hline $\mathrm{v}_{\mathrm{f}}$ (at birth) & $8.0 \times 10^{6} \mathrm{~m} / \mathrm{sec}$ & $2.4 \times 10^{7} \mathrm{~m} / \mathrm{sec}$ \\
\hline $\mathrm{n}_{\mathrm{f}}$ & $1.5 \times 10^{15} \mathrm{~m}^{-3}$ & $5.0 \times 10^{14} \mathrm{~m}^{-3}$ \\
\hline $\mathrm{p}_{\mathrm{abs}}$ & $500 \mathrm{~W} / \mathrm{m}^{3}$ (PICES result) & $500 \mathrm{~W} / \mathrm{m}^{3}$ (assumed) \\
\hline $\mathrm{v}_{\mathrm{RF}}$ & $2.0 \mathrm{sec}^{-1}$ & $2.0 \mathrm{sec}^{-1}$ \\
\hline $\mathrm{v}_{\mathrm{min}}$ & $6.9 \times 10^{6} \mathrm{~m} / \mathrm{sec}$ & $2.1 \times 10^{7} \mathrm{~m} / \mathrm{sec}$ \\
\hline$\delta \mathrm{t}$ & $0.28 \mathrm{sec}$ & $0.039 \mathrm{sec}$ \\
\hline$\delta \mathrm{v}_{\chi}$ & $4.0 \times 10^{6} \mathrm{~m} / \mathrm{sec}$ & $4.5 \times 10^{6} \mathrm{~m} / \mathrm{sec}$ \\
\hline$\delta \chi$ & $33.0^{\circ}$ & $12.3^{\circ}$ \\
\hline $\mathrm{F}_{\mathrm{RF}}$ & 1.2 & 0.70 \\
\hline
\end{tabular}

\section{Table 2}

\begin{tabular}{|l||c|c|c|}
\hline & $\mathrm{v} / \mathrm{v}_{0}$ & $\chi$ & $\cos \chi$ \\
\hline \hline $\mathrm{A}$ & 1.0 & $48.5^{\circ}$ & 0.66 \\
\hline $\mathrm{B}$ & 1.0 & $64^{\circ}$ & 0.44 \\
\hline $\mathrm{C}$ & 0.866 & $52^{\circ}$ & 0.62 \\
\hline $\mathrm{D}$ (for $1 \mathrm{MeV} \mathrm{T}$ ) & 1.0 & $19^{\circ}$ & 0.95 \\
\hline $\mathrm{D}$ (for 3 MeV p) & 1.0 & $40^{\circ}$ & 0.77 \\
\hline
\end{tabular}

\section{Figure Captions}

Figure 1: Schematic view of one of the escaping fusion product probes on TFTR. Large gyroradii ions are able to enter the probe through two apertures spaced $1 \mathrm{~cm}$ apart. The arrangement of the apertures disperses the ions in gyroradius and pitch angle across the scintillator plate. A lens and fiber optic bundle in the probe stem carry the light from the scintillator to detectors away from the tokamak.

Figure 2: Times histories of ICRF power, neutral beam power, neutron rate, and rates of loss of fusion products to detectors at $90^{\circ}, 60^{\circ}$, and $45^{\circ}$ below the outer midplane. These traces are from TFTR shot 66341, which had $\mathrm{I}_{\mathrm{p}}=1.8 \mathrm{MA}, \mathrm{R}=2.62 \mathrm{~m}, \mathrm{a}=0.99 \mathrm{~m}, \mathrm{~B}_{\mathrm{T}}=4.8$ $\mathrm{T}, \mathrm{P}_{\mathrm{NB}}=22 \mathrm{MW}, \mathrm{P}_{\mathrm{RF}}=1.8 \mathrm{MW}$ ( $5 \mathrm{~Hz}$ modulation), and $\mathrm{f}_{\mathrm{RF}}=47 \mathrm{MHz}$. The rates of fusion product loss on the $90^{\circ}$ and $45^{\circ}$ detectors follow the neutron rate, as expected, except for distinct increases synchronous with the ICRF pulses. There is no apparent modulation of the signal on the $60^{\circ}$ detector during this discharge, though in other plasmas, there is some sign of ICRF-related loss there. 
Figure 3: The fusion product loss to the $90^{\circ}$ detector, divided by the neutron rate, is plotted versus time, along with the ICRF power. There is an enhancement of the loss synchronous with the ICRF power which is about $25 \%$ above the baseline loss.

Figure 4: (a) A comparison of the gyroradius distributions on the scintillator in the $90^{\circ}$ probe with and without ICRF. (b) A comparison of the pitch angle distributions on the scintillator with and without ICRF.

Figure 5: The ratio of the ICRF enhanced loss to the first orbit loss as a function of ICRF power for 1.8 MA, $\mathrm{R}=2.62 \mathrm{~m}$ discharges in TFTR.

Figure 6: A diagram of the postulated ICRF-induced loss process. Shown are the effects of collisional slowing down and ICRF acceleration of the fusion products. The net result is that some particles are carried into the loss cone. The rate of slowing down and the rate of ICRF heating determine the range of $\chi$ at birth that will be transported into the loss cone. The point at the limit of the range of $\chi$ that will be lost due to ICRF is labeled D. 


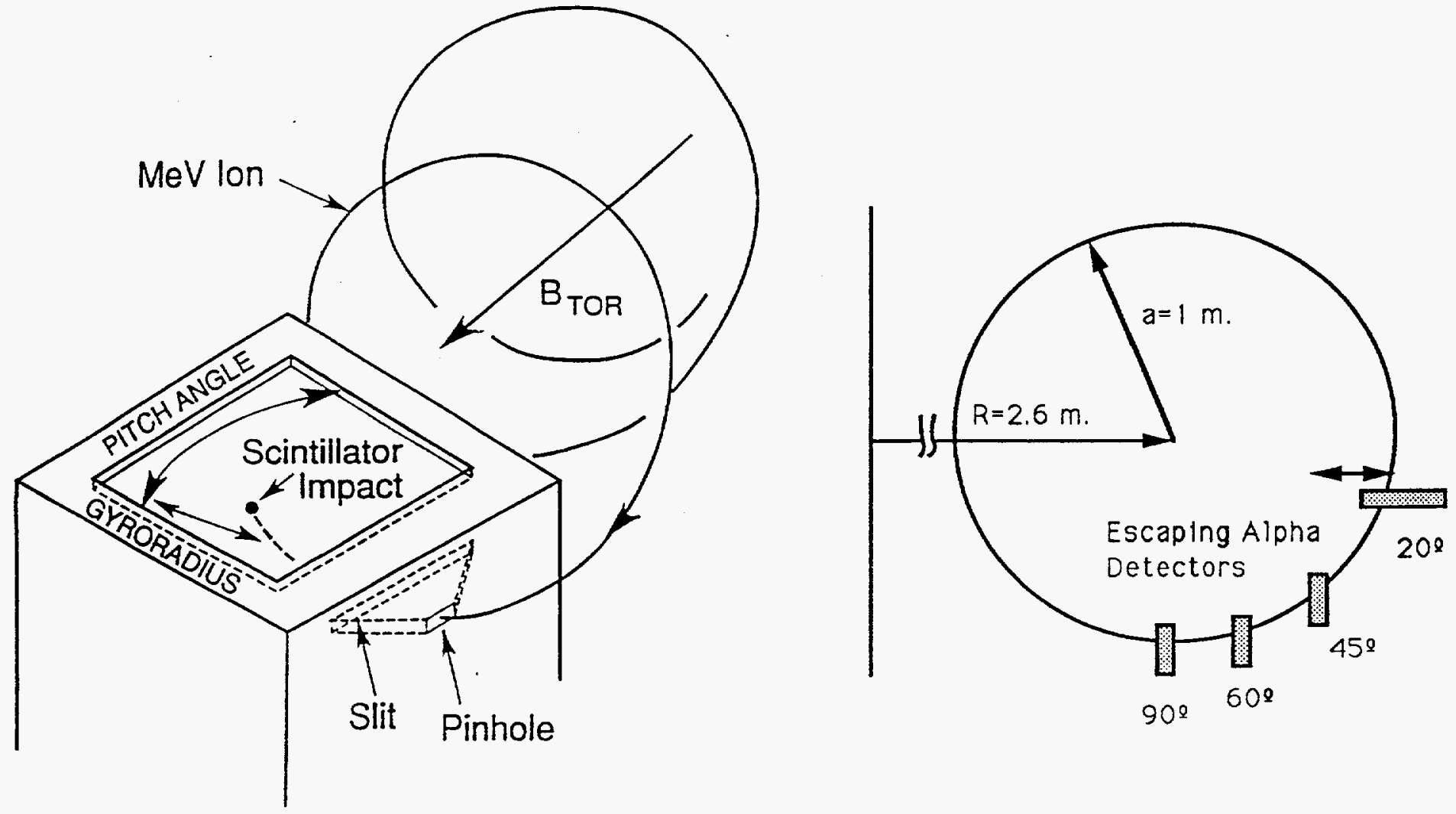

Figure 1 

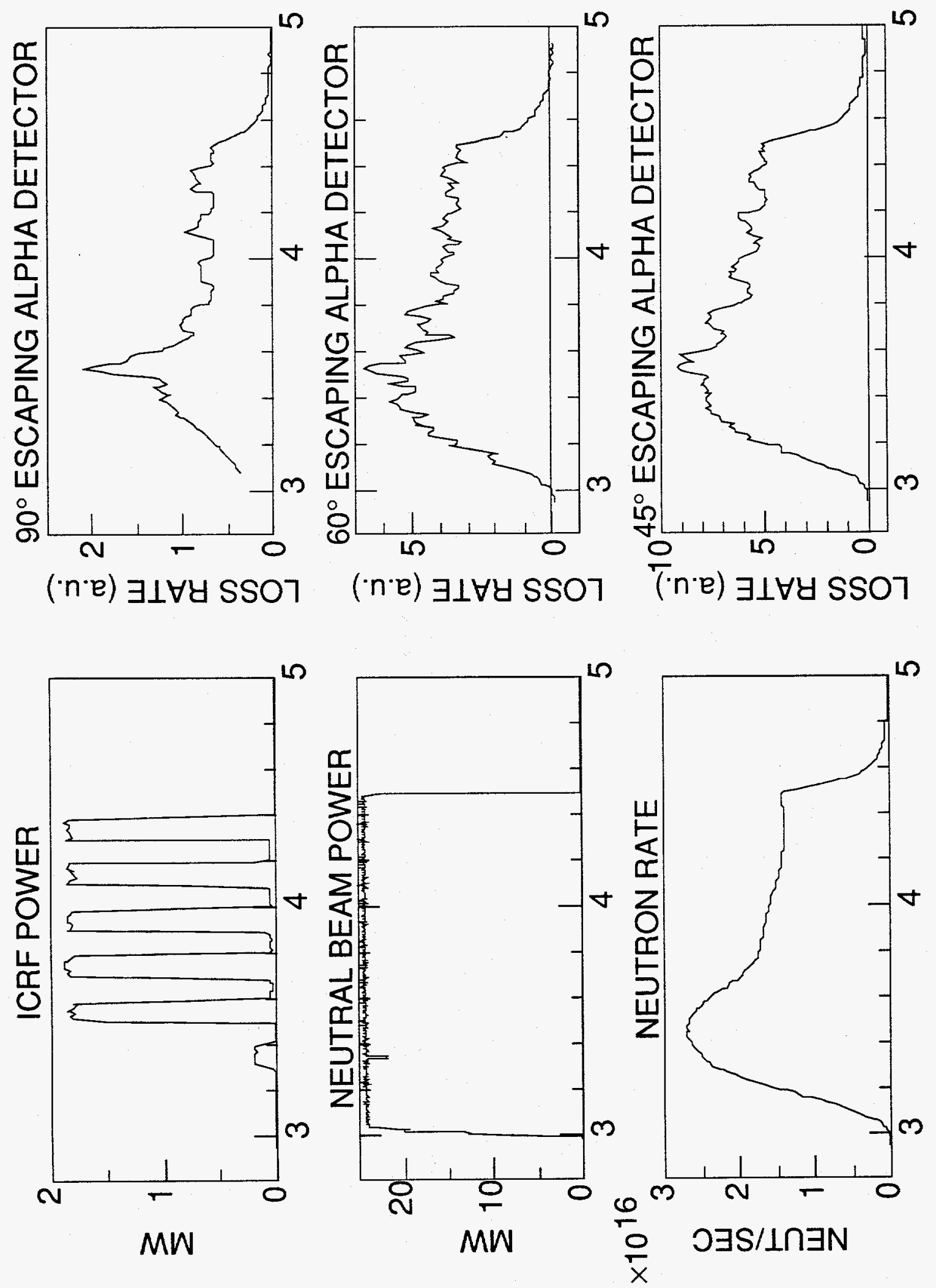

Figure 2 


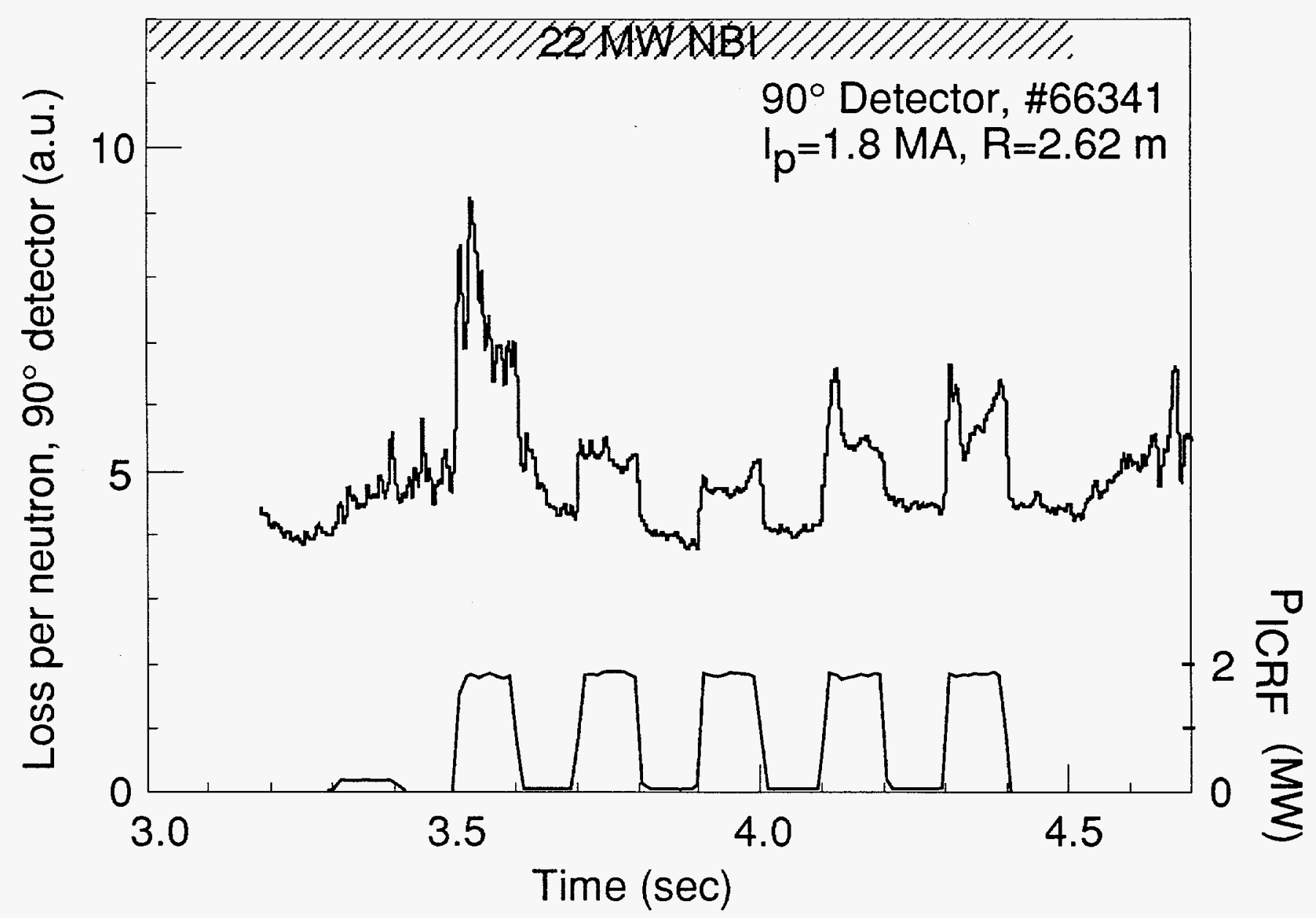

Figure 3 


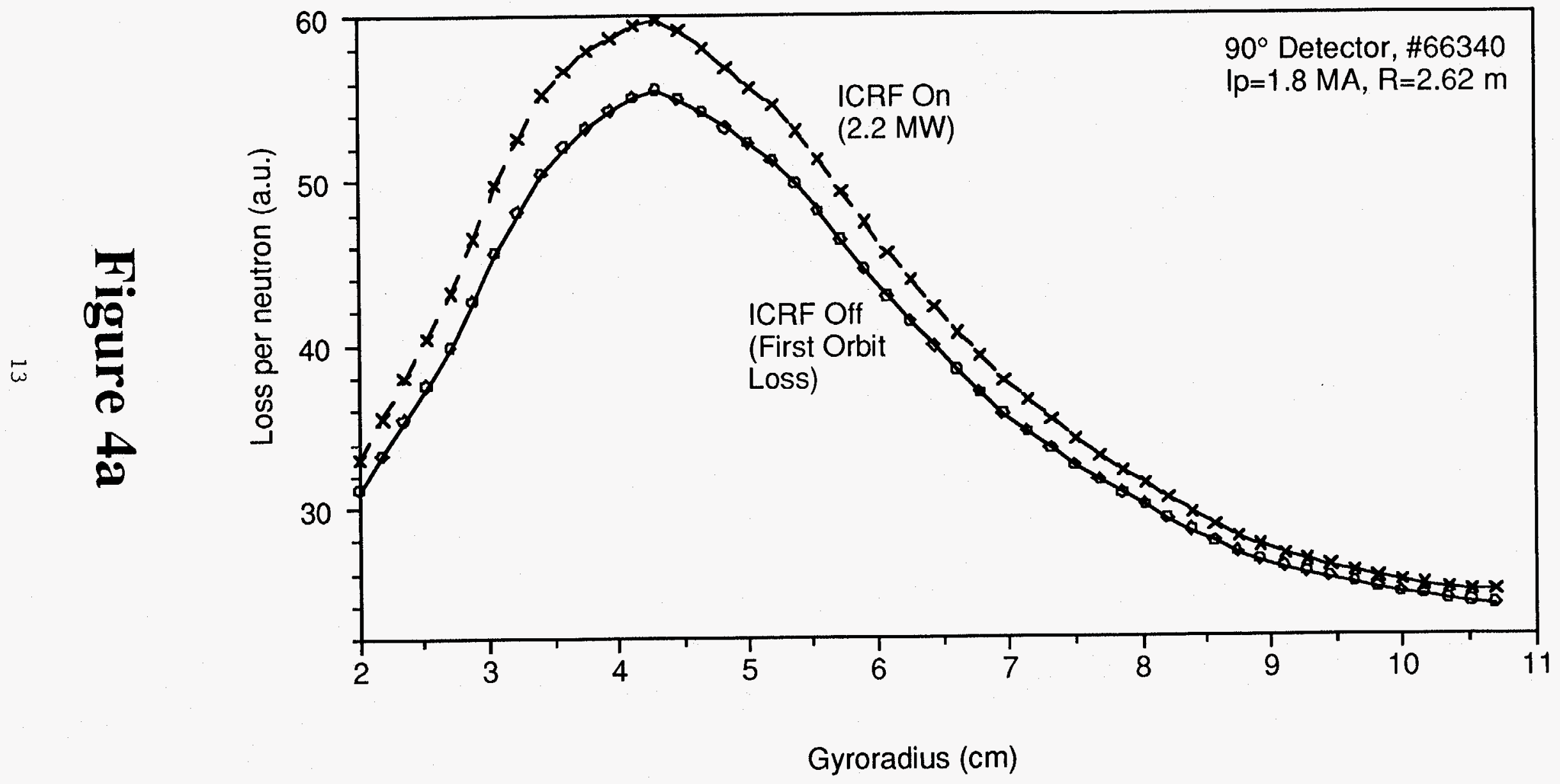




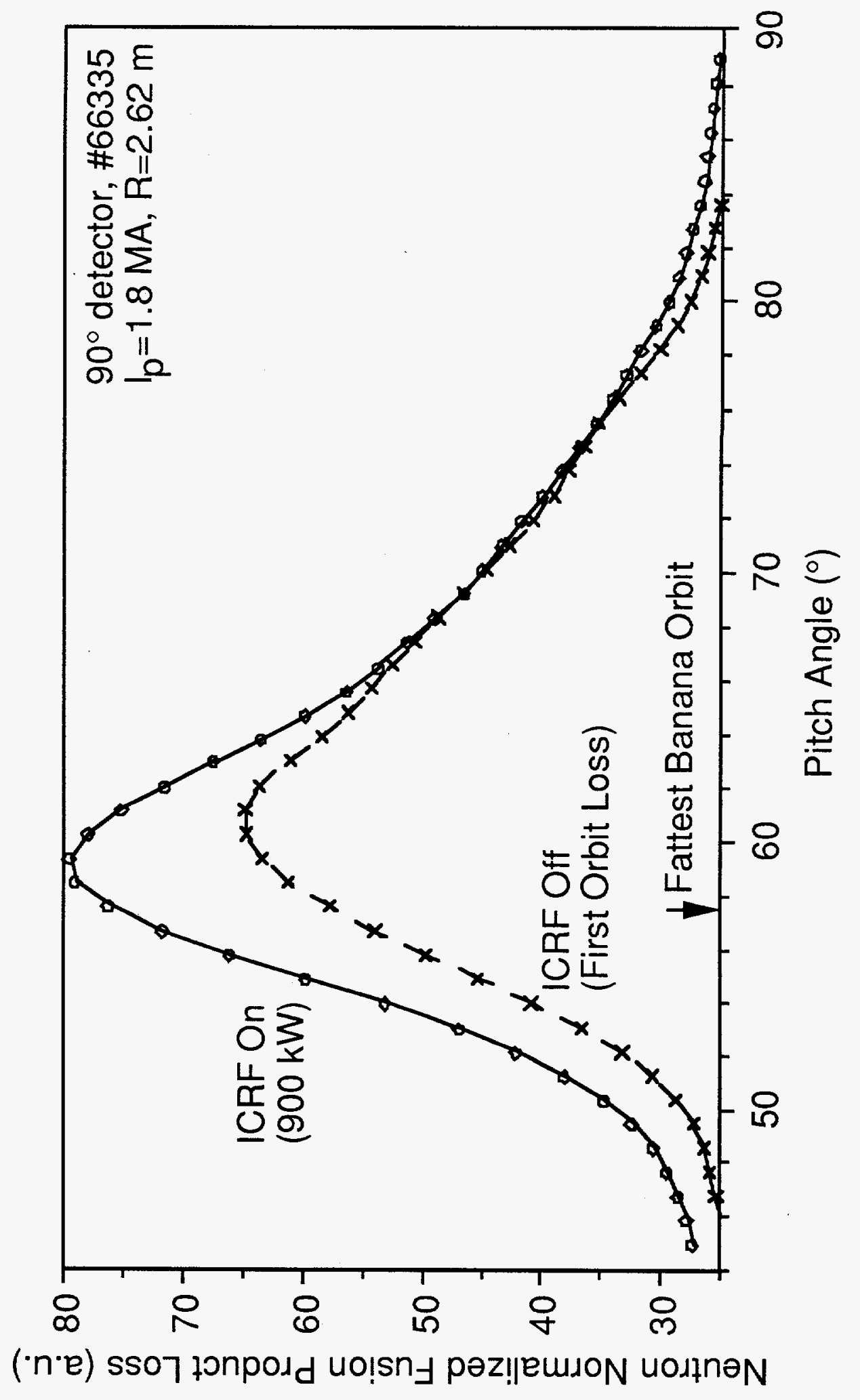

Figure 4b 


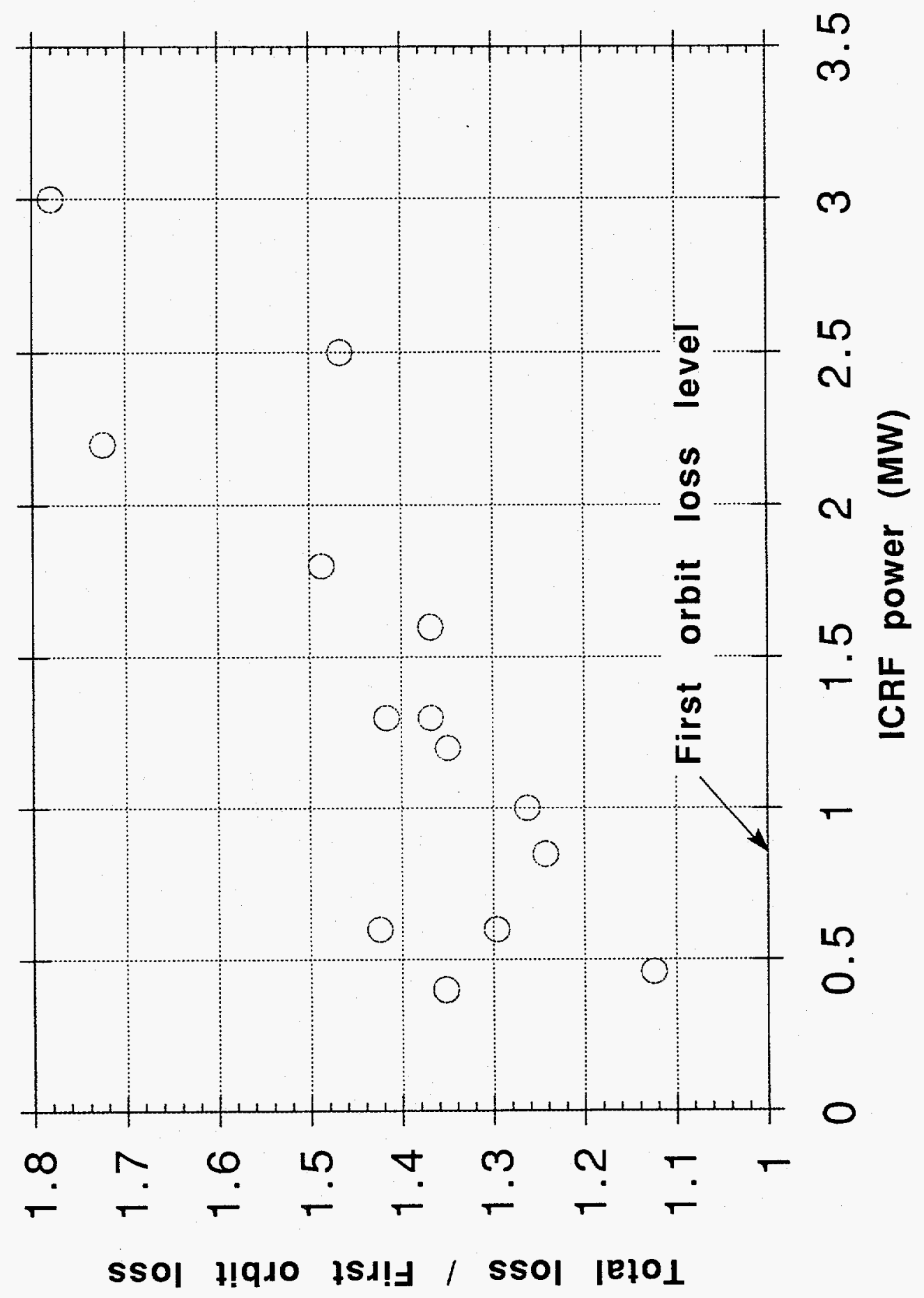

Figure 5 


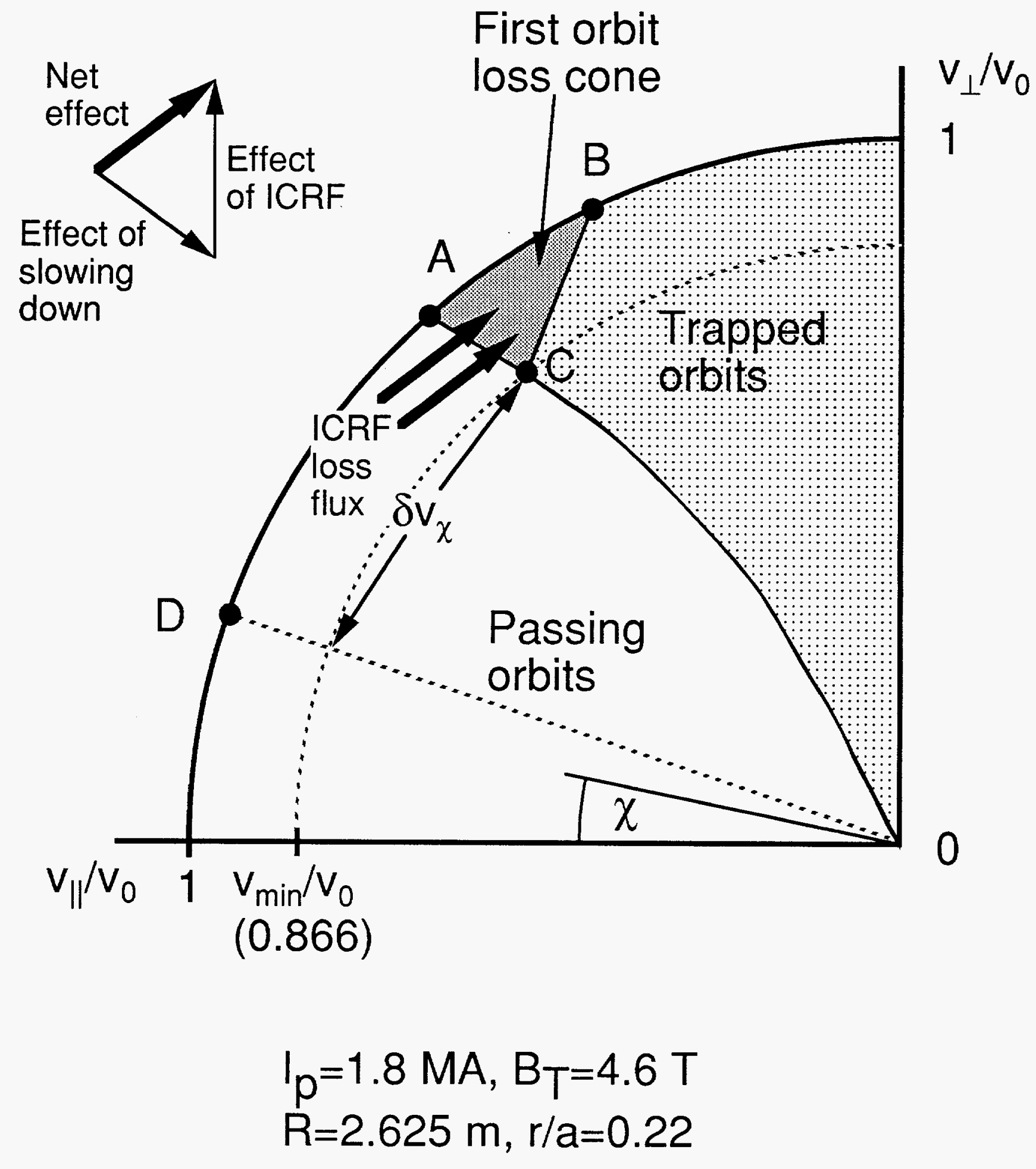

Figure 6 
Dr. F. Paoloni, Univ. of Wollongong, AUSTRALIA

Prof. R.C. Cross, Univ. of Sydney, AUSTRALIA

Plasma Research Lab., Australian Nat. Univ., AUSTRALIA

Prof. I.R. Jones, Flinders Univ, AUSTRALIA

Prof. F. Cap, Inst. for Theoretical Physics, AUSTRIA

Prof. M. Heindler, Institut für Theoretische Physik, AUSTRIA

Prof. M. Goossens, Astronomisch instituut, BELGIUM

Ecole Royale Militaire, Lab. de Phy. Plasmas, BELGIUM

Commission-European, DG. XII-Fusion Prog., BELGIUM

Prof. R. Bouciqué, Rijksuniversiteit Gent, BELGIUM

Dr. P.H. Sakanaka, Instituto Fisica, BRAZIL

Prof. Dr. I.C. Nascimento, Instituto Fisica, Sao Paulo, BRAZIL Instituto Nacional De Pesquisas Espaciais-INPE, BRAZIL Documents Office, Atomic Energy of Canada Ltd., CANADA Ms. M. Morin, CCFMTokamak de Varennes, CANADA Dr. M.P. Bachynski, MPB Technologies, Inc., CANADA Dr. H.M. Skarsgard, Univ. of Saskatchewan, CANADA Prof. J. Teichmann, Univ. of Montreal, CANADA

Prof. S.R. Sreenivasan, Univ, of Calgary, CANADA

Prof. T.W. Johnston, INRS-Energie, CANADA

Dr. R. Bolton, Centre canadien de fusion magnétique, CANADA

Dr. C.R. James, Univ. of Alberta, CANADA

Dr. P. Lukác, Komenského Universzita, CZECHO-SLOVAKIA

The Librarian, Culham Laboratory, ENGLAND

Library, R61, Rutherford Appleton Laboratory, ENGLAND

Mrs. S.A. Hutchinson, JET Library, ENGLAND

Dr. S.C. Sharma, Univ. of South Pacific, FIJI ISLANDS

P. Mähönen, Univ. of Helsinki, FINLAND

Prof. M.N. Bussac, Ecole Polytechnique, FRANCE

C. Mouttet, Lab. de Physique des Milieux lonisés, FRANCE

J. Radet, CEN/CADARACHE - Bat 506, FRANCE

Prof. E. Economou, Univ. of Crete, GREECE

Ms. C. Rinni, Univ. of loannina, GREECE

Preprint Library, Hungarian Academy of Sci., HUNGARY

Dr. B. DasGupta, Saha inst. of Nuclear Physics, INDIA

Dr. P. Kaw, Inst. for Plasma Research, INDIA

Dr. P. Rosenau, Israel Inst. of Technology, ISRAEL Librarian, International Center for Theo Physics, ITALY Miss C. De Palo, Associazione EURATOM-ENEA , ITALY Dr. G. Grosso, Istituto di Fisica del Plasma, ITALY

Prof. G. Rostangni, Istituto Gas Ionizzati Del Cnr, ITALY
Dr. H. Yamato, Toshiba Res \& Devel Center, JAPAN

Prof. I. Kawakami, Hiroshima Univ., JAPAN

Prof. K. Nishikawa, Hiroshima Univ., JAPAN

Librarian, Naka Fusion Research Establishment, JAERI, JAPAN

Director, Japan Atomic Energy Research Inst., JAPAN

Prof. S. Itoh, Kyushu Univ., JAPAN

Research info. Ctr., National Instit. for Fusion Science, JAPAN

Prof. S. Tanaka, Kyoto Univ., JAPAN

Library, Kyoto Univ., JAPAN

Prof. N. Inoue, Univ, of Tokyo, JAPAN

Secretary, Plasma Section, Electrotechnical Lab., JAPAN

Dr. O. Mitarai, Kumamoto Inst. of Technology, JAPAN

Dr. G.S. Lee, Korea Basic Sci. Ctr., KOREA

J. Hyeon-Sook, Korea Atomic Energy Research Inst., KOREA

D.I. Choi, The Korea Adv. Inst. of Sci. \& Tech., KOREA

Prof. B.S. Liley, Univ. of Waikato, NEW ZEALAND

Inst of Physics, Chinese Acad Sci PEOPLE'S REP. OF CHINA Library, Inst. of Plasma Physics, PEOPLE'S REP. OF CHINA Tsinghua Univ. Library, PEOPLE'S REPUBLIC OF CHINA Z. Li, S.W. Inst Physics, PEOPLE'S REPUBLIC OF CHINA Prof. J.A.C. Cabral, Instituto Superior Tecnico, PORTUGAL Prof. M.A. Hellberg, Univ. of Natal, S. AFRICA

Prof. D.E. Kim, Pohang Inst. of Sci. \& Tech., SO. KOREA

Prof. C.I.E.M.A.T, Fusion Division Library, SPAIN

Dr. L. Stenfio, Univ. of UMEA, SWEDEN

Library, Royal Inst. of Technology, SWEDEN

Prof. H. Wilhelmson, Chalmers Univ. of Tech., SWEDEN Centre Phys. Des Plasmas, Ecole Polytech, SWITZERLAND Bibliotheek, inst. Voor Plasma-Fysica, THE NETHERLANDS Asst. Prof. Dr. S. Cakir, Middle East Tech. Univ., TURKEY Dr. V.A. Glukhikh,Sci. Res. Inst. Electrophys.I Apparatus, USSR

Dr. D.D. Ryutov, Siberian Branch of Academy of Sci., USSR

Dr. G.A. Eliseev, I.V. Kurchatov Inst., USSR

Librarian, The Ukr.SSR Academy of Sciences, USSR

Dr. L.M. Kovrizhnykh, Inst. of General Physics, USSR

Kernforschungsanlage GmbH, Zentralbibliothek, W. GERMANY Bibliothek, Inst. Für Plasmaforschung, W. GERMANY Prof. K. Schindler, Ruhr-Universitát Bochum, W. GERMANY Dr. F. Wagner, (ASDEX), Max-Planck-Institut, W. GERMANY Librarian, Max-Planck-Institut, W. GERMANY 